Tomasz Lusiak - Andrej Novak - Martin Bugaj - Radovan Madlenak

\title{
ASSESSMENT OF IMPACT OF AERODYNAMIC LOADS ON THE STABILITY AND CONTROL OF THE GYROCOPTER MODEL
}

Aerodynamic modelling currently relates to development of mathematical models to describe the aerodynamic forces and moments acting on the aircraft. It is a challenging part of aerodynamics that defines a comprehensive approach to using traditional methods and modern techniques to obtain relevant data. The most complicated task for the aerodynamics and flight dynamics is definition, computation and quantification of the aerodynamic description of an object. This paper presents how to determine the aerodynamic load on a gyrocopter and defines the effect on its stability and control. The first step to solution is to develop simpler approximate aerodynamic model - a model that can be used in analysis of aerodynamic load and can represent the aerodynamic properties of the gyrocopter with an acceptable degree of accuracy. Control and stability are very important parts of aircraft characteristics and therefore those characteristics were analyzed in simulation. Finally, the aerodynamic data outputs are assessed in terms of impact of aerodynamic loads on stability and control of the gyrocopter model.

Keywords: aerodynamics, stability, gyrocopter, propeller

\section{Introduction}

An aircraft is a device that, using aerodynamic properties, can perform a flight in the atmosphere. Considering the principle of operation, based on which the flight is performed, aircrafts can be divided into aerostats and aerodynes. In the case of an aerostat, movement relative to the centre is not necessary. It is created in accordance with the Archimedes principle, thanks to which a load-bearing force that balances the weight is created. However, the aerodynamic movement is an indispensable element without which the flight cannot take place. Gyroplane - an aircraft heavier than air (aerodyne), from the rotorcraft family, equipped by a carrying rotor and a propeller (pushing or pulling). The impeller is not driven by the engine but rotates thanks to the autorotation of the rotorcraft relative to the air resulting from the progressive movement of the propeller.

\section{State of the art}

Aerodynamic characteristics enormously affects the aircraft performance, stability and control. The main concerns of aircraft aerodynamics are reducing drag, reducing noise and improving lift forces on aerodynamic objects. Simulation and model development are providing effective solutions in optimizing lift to drag ratios and impact of aerodynamic loads on the stability and control.
Computational Fluid Dynamics (CFD) is an analysis of the physical phenomena involved in fluid flow and heat conduction by computer numerical calculation and graphical display. The numerical method simulates the complexity of the physical problem and the precision of the numerical solution, which is directly related to the hardware speed of the computer and the hardware such as memory. With the continuous improvement of computer performance and the CFD technology, it has been widely applied to the field of water conservancy engineering, environmental engineering and industrial engineering. The CFD technology in the mechanical engineering related applications are summarized [1].

\section{Methodology}

The gyroplane model is a composite structure with a central steel lattice in which the drive unit will be placed inside. Rotorcraft cabin Aduster is a completely closed, two-seater structure. The system uses the so-called "Inverted V", which has a stationary part and a movable steering part. The four-point chassis system consists of a main shin hidden and mounted in the tail system of the rear legs of the chassis. The control system is divided according to the three axes of the aircraft (longitudinal axis, transverse axis and normal axis). The control of the rotor system, understood as inclination and tilting, is carried out using a control stick located at each of the two places in

Tomasz Lusiak ${ }^{1}$, Andrej Novak ${ }^{2}$, Martin Bugaj², Radovan Madlenak ${ }^{2, *}$

${ }^{1}$ Lublin University of Technology, Poland

${ }^{2}$ University of Zilina, Slovakia

*E-mail of corresponding author: radovan.madlenak@fpedas.uniza.sk 


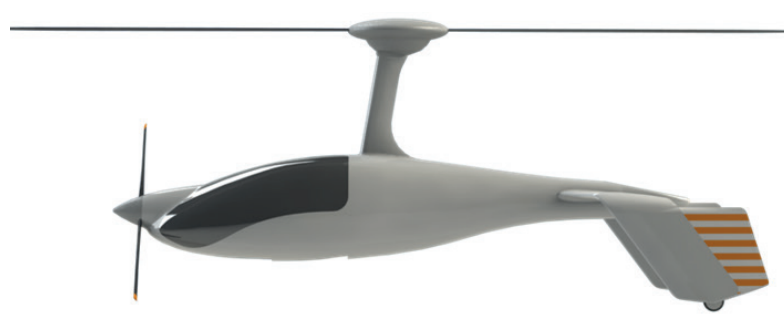

Figure 1 Visualization of the gyroplane prototype

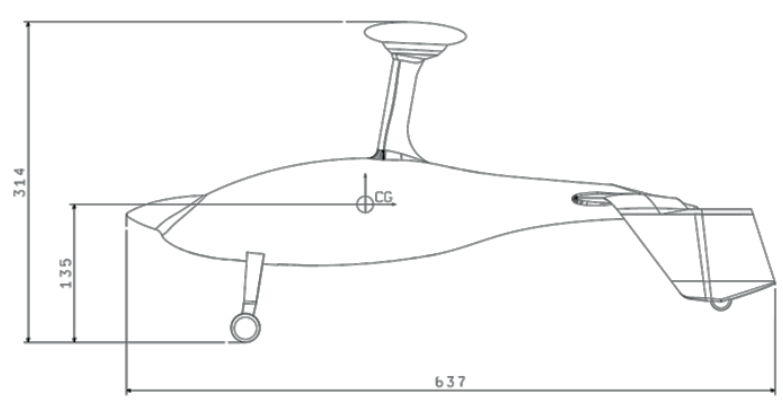

Figure 2 Lateral view of the gyroplane

the cabin [2]. The tilting of the rod to itself will increase the angles of attack, thus increasing the angle of attack of the aircraft and recruitment of heights. In order to make a turn, the control stick should be tilted to the side, which will cause the side of the rotor to tilt in the same direction. Application of the inverted $V$ type enables the bend to be made without changing the rotor deflection, but only when the rudder is tilted [3].

\subsection{The geometrical model}

Gyroplane differs from the current designs of rotorcraft companies: CelierAviation, AutoGyro, MagniGyro, ELA Aviation, because of the engine's location and use of a pulling propulsor instead of a pusher. This project will be characterized by higher performance and less complexity of the engine-propeller system. Due to its highly aerodynamic design, the gyro Aduster is characterized by the low air resistance. The model used during the tests was provided by the ordering party. Figures 1-3 show a side view and a plan view of the gyrocopter concept [4].

The aerodyne model was made in the 1:8 scale, and the detailed height and length dimensions were given on two views of the technical drawing (Figure 4). The windmill during the tests in the wind tunnel is devoid of propellers and rotor blades. The extension consists of a double vertical stabilizer with rudders and a horizontal stabilizer with height controls. The mast is placed so that the gondola touches the center of gravity of the aircraft. During the experiments different geometric configurations were used, which will be discussed later in the work. The aircraft

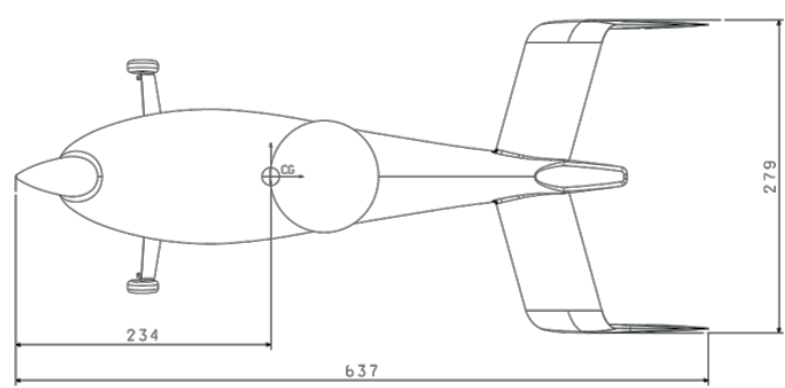

Figure 3 Upper view of the gyroplane

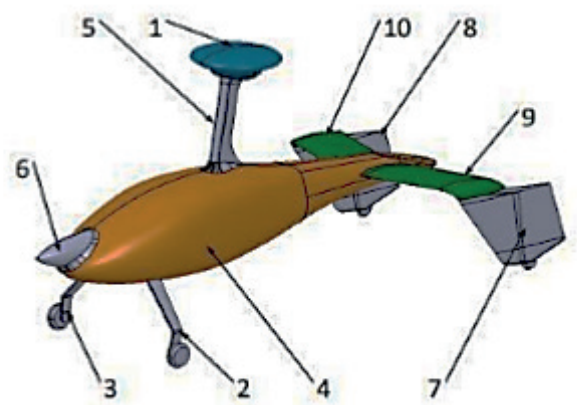

Figure 4 Specification of a gyroplane: 1 - head, 2 - left shank, 3 - right shank, 4 - hull, 5 - pole, 6 - nose, 7 - left vertical stabilizer, 8 - right vertical stabilizer, 9 - left horizontal stabilizer, 10 - right horizontal stabilizer

and model real dimensions included in the table below were used to size forces and moments to the appropriate coefficients.

\section{Developing of the Aduster model}

The aerodynamic tunnel is the basic research device for experimental aerodynamics. The most important part of each aerodynamic tunnel is the area (test chamber) in which the test object or its research model is placed. The tunnel, in addition to the chamber, consists of devices that generate a stream of air flowing around the object under test. The air acts in the same way on the object being examined, as if the object was moving and the air was still. This enables precise measurements of forces and moments, as well as flow visualizations. The tests were carried out in the wind tunnel of the Institute of Aviation in Warsaw [5]. The wind tunnel, test stand has a closed cycle with an open measuring space with a circular cross-section. Inside the open measuring space, a positioning system is installed that allows the model to be installed. The research was carried out using a multicomponent sensor of forces and moments of the so-called aerodynamic weight 6-component. The center of the balance (reference point of the measured forces) is located in the middle of the rotation of the positioning system. The measuring system works in automatic mode, eating the model positions based on the prepared angle grid. The measurement performed is the effect of registering the value of the determined average with the test of the stationarity of the result [6-7]. 
Table 1 Measurement of impact of weight of the "dynamic tare" model

\begin{tabular}{|c|c|c|c|c|c|c|}
\hline Alfa & Beta & $\mathrm{Fz}$ & $\mathrm{Fx}$ & $\mathrm{Cx}$ & $\mathrm{Cz}$ & $\mathrm{Cz} / \mathrm{Cx}$ \\
\hline-20 & -10 & -9.4265 & 4.2926 & 0.0091 & -0.0199 & -2.1960 \\
\hline-16 & -10 & -7.0512 & 3.4726 & 0.0073 & -0.0149 & -2.0306 \\
\hline-12 & -10 & -4.1464 & 2.9072 & 0.0061 & -0.0087 & -1.4263 \\
\hline-8 & -10 & -1.2058 & 2.6106 & 0.0055 & -0.0025 & -0.4619 \\
\hline-4 & -10 & 1.9721 & 2.5099 & 0.0052 & 0.0041 & 0.7857 \\
\hline-2 & -10 & 3.5317 & 2.5703 & 0.0054 & 0.0074 & 1.3741 \\
\hline 0 & -10 & 5.3060 & 2.6047 & 0.0054 & 0.0110 & 2.0371 \\
\hline 2 & -10 & 6.2942 & 2.8810 & 0.0060 & 0.0131 & 2.1847 \\
\hline 4 & -10 & 7.4409 & 3.3982 & 0.0071 & 0.0155 & 2.1896 \\
\hline 8 & -10 & 8.2456 & 4.4648 & 0.0093 & 0.0171 & 1.8468 \\
\hline 12 & -10 & 9.1378 & 5.4436 & 0.0113 & 0.0189 & 1.6786 \\
\hline 16 & -10 & 10.0007 & 6.4279 & 0.0133 & 0.0207 & 1.5558 \\
\hline 20 & -10 & 11.0049 & 7.5269 & 0.0156 & 0.0229 & 1.4621 \\
\hline-20 & 0 & -8.97146 & 3.685696 & 0.007641 & -0.0186 & -2.43413 \\
\hline-16 & 0 & -6.66635 & 2.923756 & 0.006031 & -0.01375 & -2.28006 \\
\hline-12 & 0 & -3.75749 & 2.48963 & 0.005135 & -0.00775 & -1.50926 \\
\hline-8 & 0 & -0.44951 & 2.212088 & 0.004541 & -0.00092 & -0.20321 \\
\hline-4 & 0 & 2.878314 & 2.097328 & 0.004307 & 0.005911 & 1.372372 \\
\hline-2 & 0 & 4.554367 & 2.137357 & 0.004388 & 0.00935 & 2.130841 \\
\hline 0 & 0 & 5.933 & 2.159 & 0.004426 & 0.012163 & 2.748031 \\
\hline 2 & 0 & 7.096112 & 2.241016 & 0.004593 & 0.014543 & 3.166471 \\
\hline 4 & 0 & 8.20449 & 2.687864 & 0.005511 & 0.016823 & 3.05242 \\
\hline 8 & 0 & 9.112066 & 3.791049 & 0.007791 & 0.018726 & 2.403574 \\
\hline 12 & 0 & 9.464429 & 4.595181 & 0.009441 & 0.019445 & 2.059642 \\
\hline 16 & 0 & 9.97885 & 5.176055 & 0.010669 & 0.020568 & 1.927887 \\
\hline 20 & 0 & 10.99508 & 6.061065 & 0.012465 & 0.022612 & 1.81405 \\
\hline-20 & 10 & -9.28013 & 4.420572 & 0.009071 & -0.01904 & -2.0993 \\
\hline-16 & 10 & -7.00537 & 3.527572 & 0.007226 & -0.01435 & -1.98589 \\
\hline-12 & 10 & -3.87517 & 2.950275 & 0.006035 & -0.00793 & -1.31349 \\
\hline-8 & 10 & -0.79507 & 2.631817 & 0.005379 & -0.00163 & -0.3021 \\
\hline-4 & 10 & 2.349215 & 2.458541 & 0.005025 & 0.004802 & 0.955532 \\
\hline-2 & 10 & 3.805268 & 2.491261 & 0.005107 & 0.007801 & 1.527447 \\
\hline 0 & 10 & 5.824576 & 2.63908 & 0.005401 & 0.011317 & 2.095427 \\
\hline 2 & 10 & 7.059668 & 2.852268 & 0.005837 & 0.014447 & 2.475107 \\
\hline 4 & 10 & 8.532465 & 3.373581 & 0.006901 & 0.017453 & 2.529202 \\
\hline 8 & 10 & 9.406529 & 4.544506 & 0.009319 & 0.019288 & 2.069868 \\
\hline 12 & 10 & 10.01453 & 5.515316 & 0.011326 & 0.020565 & 1.815766 \\
\hline 16 & 10 & 10.55115 & 6.463266 & 0.013335 & 0.02177 & 1.632479 \\
\hline 20 & 10 & 11.67543 & 7.555151 & 0.015576 & 0.024071 & 1.54536 \\
\hline
\end{tabular}

Measuring space dimensions: $\mathrm{D}=1.2 \mathrm{~m}, \mathrm{~L}=1.5 \mathrm{~m}$. Dimension from the PP inlet to the axle: $1=0.443 \mathrm{~m}$ Air speed: up to $40 \mathrm{~m} / \mathrm{s}$

Angle ranges: $\alpha \in<-30 ; 25>$ and $\beta \in<-25 ; 25>$

\section{Stability and control of the aircraft}

Behavior of the aircraft after the impact of the disturbing force on it characterizes these properties of undisturbed aircraft movement, which are known as stability and 


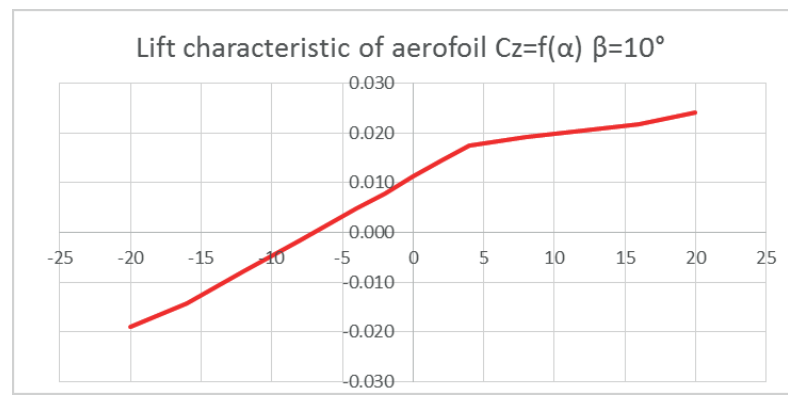

Figure 5 Aerodynamic coefficients power of lift obtained during the measurements for the slip angle $\beta=10^{\circ}$

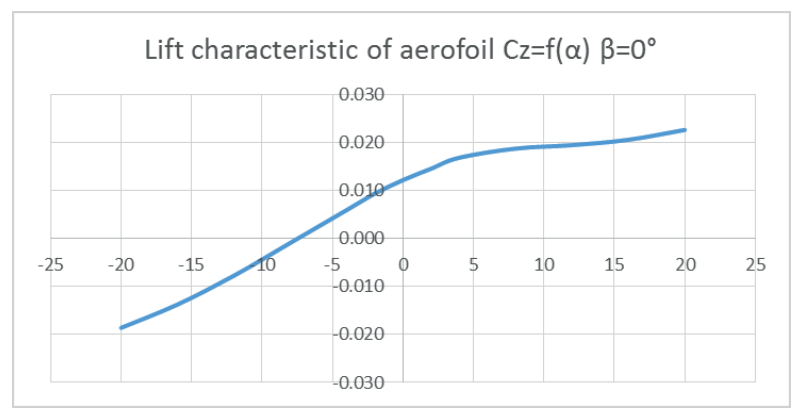

Figure 6 Aerodynamic coefficients power of lift obtained during the measurements for the slip angle $\beta=0^{\circ}$

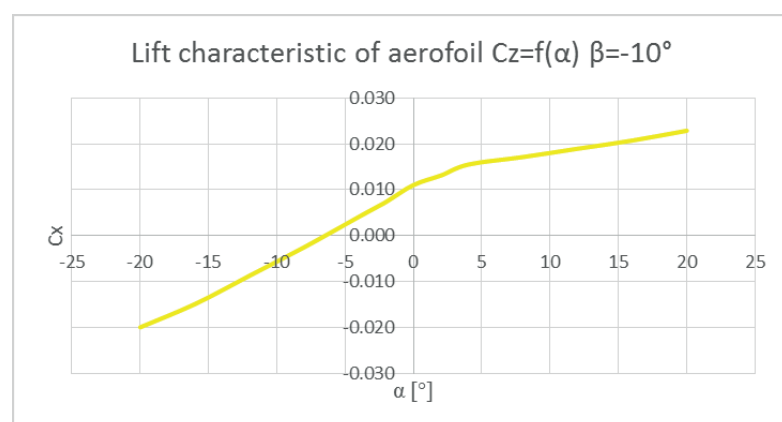

Figure 7 Aerodynamic coefficients power of lift obtained during the measurements for the slip angle $\beta=-10^{\circ}$

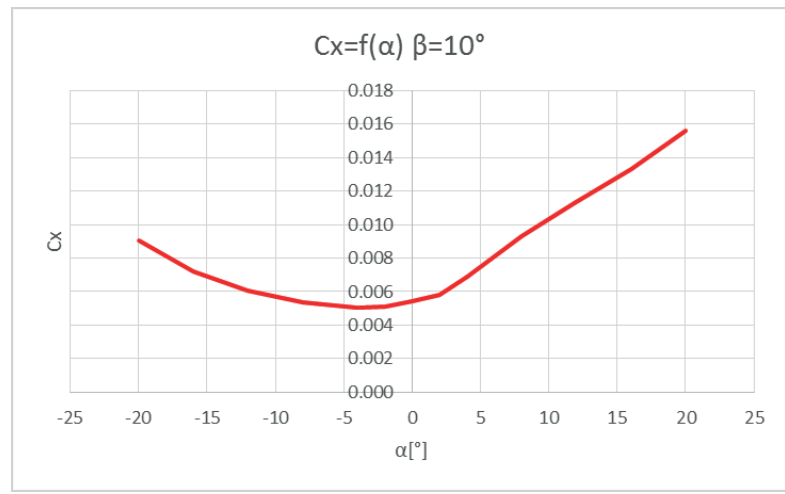

Figure 8 Aerodynamic coefficients power of drag obtained during the measurements for the slip angle $\beta=10^{\circ}$

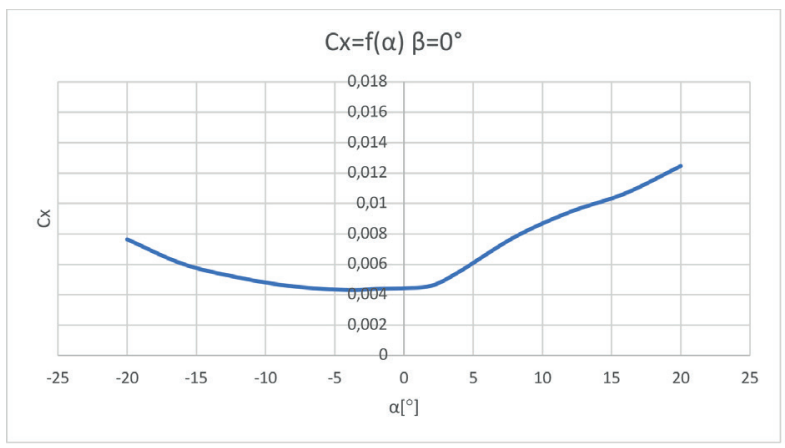

Figure 9 Aerodynamic coefficients power of drag obtained during the measurements for the slip angle $\beta=0^{\circ}$

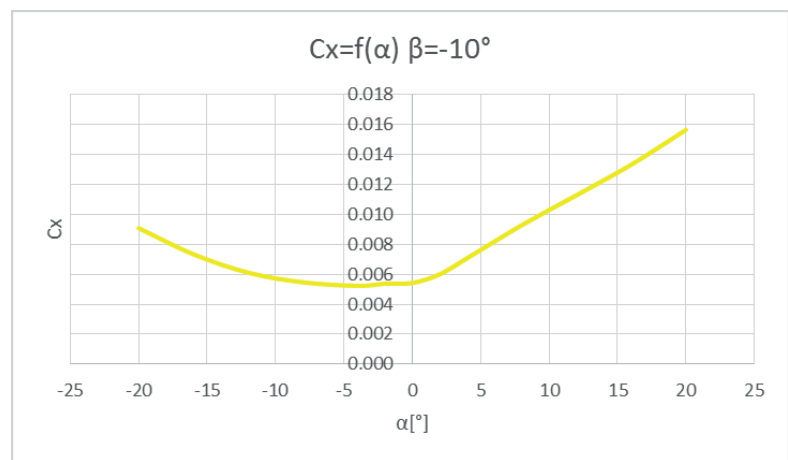

Figure 10 Aerodynamic coefficients power of drag obtained during the measurements for the slip angle $\beta=-10^{\circ}$

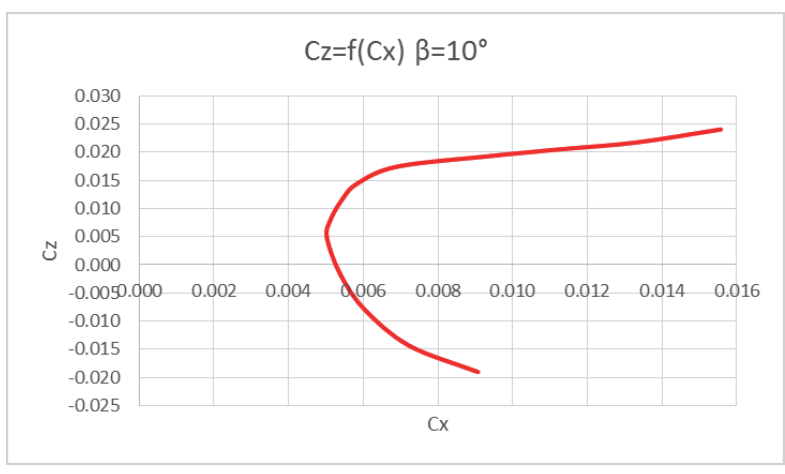

Figure 11 Aerodynamic coefficients obtained during the measurements for the slip angle $\beta=10^{\circ}$

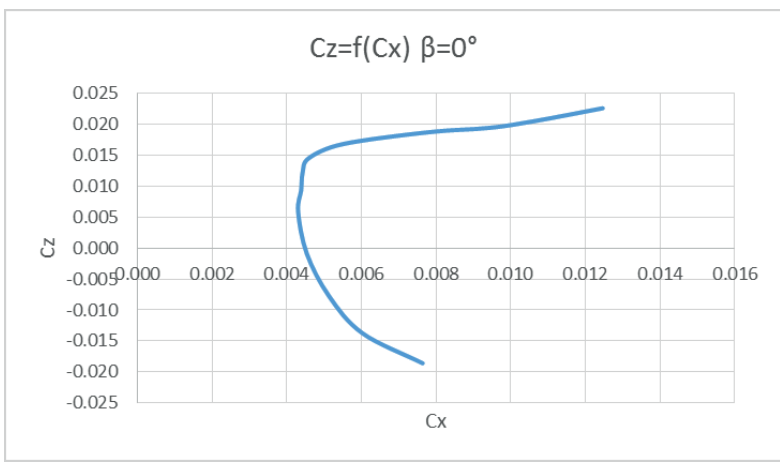

Figure 12 Aerodynamic coefficients obtained during the measurements for the slip angle $\beta=0^{\circ}$ 


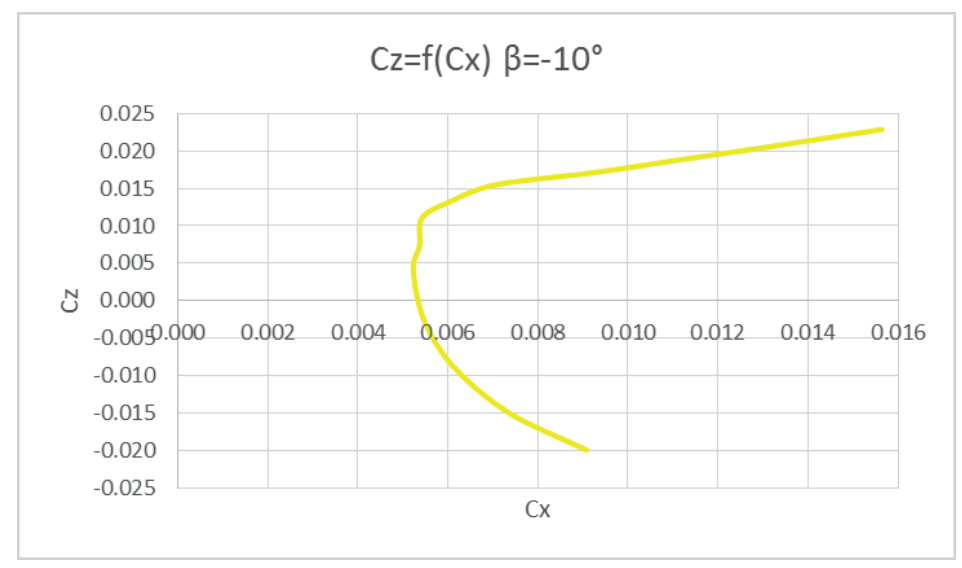

Figure 13 Aerodynamic coefficients obtained during the measurements for the slip angle $\beta=-10^{\circ}$

instability [8]. The necessary condition for the aircraft to move is not only the balance of all the forces acting on the plane, but also the balance of moments relative to the three coordinate axes (x, y, z) passing through its center of gravity. The plane's balance should be stable, that is, the plane derived from the equilibrium by some external factor, such as a blast, should return to the state of balance in a sufficiently short time without the intervention of the pilot (at least when the disturbance was not too high). The concepts of stability and balance are therefore closely related. When talking about stability, it is assumed that there is a balance, otherwise the notion of stability would not make sense. The static stability of an aircraft is called its ability to return independently (without the participation of the pilot) to the position of equilibrium, when the causes that break this balance cease to function. The dynamic stability, on the other hand, determines the type of movements that an airplane performs by returning to the equilibrium position (e.g. number, amplitude and time of deflections). The issues of static and dynamic stability are closely and inseparably connected, however, for the plane to be dynamically stable, it must be static [9]. The plane's stability with respect to the y axis is called longitudinal stability; it is secured by height. The stability with respect to the $\mathrm{x}$ and $\mathrm{z}$ axes, provided by the sash lift and the direction, is called the lateral and directional, respectively, but they are considered jointly as the lateral stability, since they are closely related to each other. These properties of undisturbed aircraft movement are known as stability and instability. The necessary condition for the aircraft to move is not only the balance of all the forces acting on the aircraft, but also the balance of moments relative to the three coordinate axes (x,y, z) passing through its center of gravity. The aircraft's balance should be stable, that is, the aircraft derived from the equilibrium by some external factor, such as a blast, should return to the state of balance in a sufficiently short time without the intervention of the pilot (at least when the disturbance was not too high). The concepts of stability and balance are therefore closely related [10].

\section{The simulation assessment}

Preparatory activities, related to assembly of the model were carried out in the following stages. The model was delivered in elements made of FDM 3D printing. The elements required matching, assembly and finishing. The activities were carried out: matching of elements and introduction of elements strengthening the internal structure and elements ensuring surface compatibility; assembly and gluing of the model; sanding and painting the external surface of the model to ensure smoothness [11].

The measurement series listed in Table 1 were implemented in the predefined positions of the model using the so-called grid of points in the space of angles. Measurement of individual measurement series was performed according to the procedure: measurement of the tare reference signal; before each measurement series, a reference signal was measured corresponding to signals in the unladen system; the measured signal is subtracted later in the measuring series from the measured signal.

Measurement of impact of the weight of the "dynamic tare" model. At each configuration, a signal measurement of forces acting on the measurement system was carried out at the changing setting of the model without aerodynamic interactions. In this measurement, impact of the weight of the model is determined at changing angles of the model's positioning. With the model placed in the measurement system in the horizontal position of the orientation of its symmetry plane, the gravity of the model mainly acts in the OY axis direction of the model, i.e. on the $\mathrm{C}$ measurement component. When the angle of the slide changes $\beta$ gravity force affects the $\mathrm{OX}$ direction of the model, i.e. the $\mathrm{X}$ measurement component [12].

In this section, graphs of the Advent gyroplane characteristics are presented for selected angles of attack in relation to the slip angles. The research was carried out in several geometrical configurations. Values of selected aerodynamic coefficients, obtained during the measurements, are presented in the characteristics' graphs (see Figures 5-13). The characteristics in red are for the slip 
angle $\beta=10^{\circ}$, the blue ones correspond to the zero-slip angle and the yellow ones are $\beta=-10^{\circ}$.

\section{Conclusions}

In this project the study about the aerodynamic characteristics of the aircraft - the Aduster gyroplane was dealt with. The purpose of the paper was to assess the impact of aerodynamic loads on the stability and control of the gyroplane model at various geometric configurations [13].

The graphs presenting $\mathrm{Cz}=f(\alpha)$ (see Figures 5-7) are similar in shape to the characteristics in literature. There are minimal changes in the graphs under the influence of different slip angle. Characteristics of the drag coefficient as a function of the angle of attack $\mathrm{Cx}=f(\alpha)$ is similar in shape to the characteristics in the literature - there is induced resistance. In the case of angle of attack equal zero, $\mathrm{Cx}$ is the smallest (Figure 9 ). For the slip angle $-10^{\circ}$ $\mathrm{Cx}$ is bigger (Figure 10), and for the slip angle $10^{\circ} \mathrm{Cx}$ is the largest (Figure 8), but the difference is not so big. The polar profile - Lilienthal's Curve $\mathrm{Cz}=f(\mathrm{Cx})$ is similar in shape to characteristics in the literature. On the polar airfoil one can notice a small outline of the laminar profile, which has better properties for a range of small angles of attack (low value of the lift force). For the slip angle equal zero (Figure 12) the range of $\mathrm{Cx}$ values is the smallest, and in the case of slip angles different than zero there is a greater spread of graphs in relation to $\mathrm{Cz}$, which indicates a higher coefficient of lift. Characteristics of airfoil attitude
$\mathrm{Cz} / \mathrm{Cx}$ in the case of a zero-slip angle as a function of the angle of attack is similar in shape to the characteristics in the literature. In the case of a slip angle of $10^{\circ},-10^{\circ}$, the diagrams have a smaller spread. The characteristics of the moment coefficient as a function of the angle of attack $\mathrm{Mz}$ $=f(\alpha)$ indicates the zero value of the moment coefficient as a function of the angle of attack for the graph showing the negative slip angle. The graph for the value of the slip angle equal zero assumes the smallest span of values. In the case of the slip angle $10^{\circ}$ the moment coefficient takes positive values (Figure 13) and in the case of the slip angle $-10^{\circ}$ the moment coefficient takes negative values (Figure 11).

Comparing individual graphs for given slip angles, one can notice slight differences between the angle of attack equal zero and its limit values. Having that considered and with the use of appropriate mathematical formulas, one can calculate the drag forces or the lifting force for the entire structure. The obtained result also illustrates how much one would have to increase other parameters, e.g. flight speed, to maintain the horizontal flight conditions.

\section{Acknowledgements}

This publication was realized with support of Operational Program Integrated Infrastructure 2014 2020 of the project: Innovative Solutions for Propulsion, Power and Safety Components of Transport Vehicles, code ITMS 313011V334, co-financed by the European Regional Development Fund.

\section{References}

[1] YUFENG, W: The development and application of CFD technology in mechanical engineering. IOP Conference Series: Materials Science and Engineering [online]. 2017, 274, 012012. ISSN 1757-8981, eISSN 1757-899X. Available from: https://doi.org/10.1088/1757-899X/274/1/012012

[2] COMPA, T. Fundamentals of aircraft knowledge / Podstawy wiedzy o statkach powietrznych (in Polish:). Deblin: WSOSP, 2012. ISBN 9788360908068.

[3] LUSIAK, T., WENDEKER, M. Aerodynamic testing of a fuselage gyroplanel Badania aerodynamiczne kadluba wiatrakowca Ruchala (in Polish). Report of project. 2013.

[4] LUSIAK, T., WENDEKER, M. Aerodynamic research of Fusioncopter the fuselage gyroplane/Badania aerodynamiczne kadluba wiatrakowca Fusioncopter (in Polish). 2/92/NN/2013. Lublin: Lublin University of Technology, Department of Thermodynamic, fluid Mechanics and Aviation Propulsion Systems, 2013.

[5] WISNIOWSKI, W. Wind tunnels in Poland against the background of world tunnels / Tunele aerodynamiczne w Polsce na tle tuneli swiatowych (in Polish). Warszawa: Wydawnictwo Naukowe Instytutu Lotnictwa, 2016. ISBN 978-83-6353-928-3.

[6] BARLOW, J., RAE, W. H., POPE, A. Low-speed wind tunnel testing. 3. ed. Wiley-Interscience, 1999. ISBN 978-0471557746.

[7] CZYZ, Z., LUSIAK, T., MAGRYTA, P. Numerical CFD tests for impact on the aerodynamic characteristics of the gyroplane/ Badania numeryczne CFD wplywu usterzenia na charakterystyki aerodynamiczne wiatrakowca (in Polish:). Prace Instytutu Lotnictwa [online]. 2013, 232, p. 3-14. ISSN 0509-6669, eISSN 2300-5408. Available from: https://doi.org/10.5604/05096669.1106582

[8] SMYKLA, I. Selected issues in aerodynamics and flight mechanics (flight rules)-notes / Wybrane zagadnienia z aerodynamiki i mechaniki lotu (zasady lotu) (in Polish). Warszawa, 2008.

[9] Sciendo [online] [accessed 2018-04-06]. Available from: https://content.sciendo.com 
[10] SOBIERAJ, W. Theory of the aerodynamics/ Aerodynamika (in Polish). Warszawa: Wojskowa Akademia Techniczna, 2014. ISBN 978-83-7938-044-2.

[11] Printers 3D / Drukarki 3D (in Polish) - Bibus Menos [online]. Available from: https://drukarki3d.pl/technologie/fdm/

[12] RUCHALA, P., STRYCZNIEWICZ, W., CZYZ, Z., LUSIAK, T. Aerodynamic characteristics of the hull of a windmill for various angles of horizontal impact / Charakterystyki aerodynamiczne kadluba wiatrakowca dla roznych katow zaklinowania usterzenia poziomego (in Polish). The work of the Institute of Aviation [online]. 2015, 241(4), p. 96-107. ISSN 0509-6669, eISSN 2300-5408. Available from: https://doi.org/10.5604/05096669.1202198

[13] LUSIAK, T., CZYZ, Z., KLODA, L., CHABROS, M., DZAMAN, E. Comparative analysis of the results of numerical tests of a windmill with the results of tests in an aerodynamic tunnel / Analiza porownawcza wynikow badan numerycznych wiatrakowca z wynikami badan w tunelu aerodynamicznym (in Polish:). In: Progress in manufacturing techniques and machine construction: selected problem areas. RUDAWSKA, A., JACHOWICZ, T.,KLONICA, M. (eds.). Lublin: Perfekta info, 2013. ISBN 978-83-63657-09-3, p.5-18. 